\title{
Aquaporin 4 inhibition decreased synthesis of cytokines by acetazolamide in the hippocampus of rats with pentrazol-induced chronic epilepsy
}

\author{
H. Yu ${ }^{1}$, G.L. Qi ${ }^{2}$, J. Wang ${ }^{2}$, L. Chen ${ }^{3}$, Z. Deng ${ }^{3}$, Y.S. Zhao ${ }^{3}$, S.S. Lei ${ }^{4}$ and \\ X.Q. $\mathbf{Z h u}^{3}$ \\ ${ }^{1}$ Department of Pathology, \\ The Affiliated Hospital of Hubei University of Medicine, \\ Xiangyang First People's Hospital, Xiangyang, China \\ ${ }^{2}$ Department of Obstetrics and Gynecology, \\ The Affiliated Hospital of Hubei University of Medicine, \\ Xiangyang First People's Hospital, Xiangyang, China \\ ${ }^{3}$ Department of Physiology, Guangzhou Medical University, \\ Guangzhou, China \\ ${ }^{4}$ The Fifth Affiliated Hospital of Guangzhou Medical University, \\ Guangzhou, China
}

Corresponding author: X.Q. Zhu

E-mail:whzhuxiaoqin@163.com

Genet. Mol. Res. 15 (3): gmr.15039012

Received July 21, 2016

Accepted August 1, 2016

Published September 23, 2016

DOI http://dx.doi.org/10.4238/gmr.15039012

Copyright (C) 2016 The Authors. This is an open-access article distributed under the terms of the Creative Commons Attribution ShareAlike (CC BY-SA) 4.0 License.

\begin{abstract}
Epilepsy refers to a clinical syndrome generated by spontaneous seizures in the central nervous system. Epilepsy triggers a complex pathological process including inflammatory response and aquaporin 4 (AQP4) increase. It has been reported that AQP4 helps to enhance the immunological function of the central nervous system in pathological conditions, but the relationship between AQP4 and
\end{abstract}


inflammatory cytokines is poorly understood in chronic epilepsy processes. As an inhibitor of sulfonamide carbonic anhydrase (CA), acetazolamide (AZA) may inhibit water infiltration through AQP4. In this context, pentylenetetrazole (PTZ) is used to induce the chronic epilepsy model in rats to study the chronic epilepsy effects of AQP4 inhibition on proinflammatory cytokine expression in the hippocampus and proinflammatory cytokine quantification analysis of the plasma. Based on the assumption that AQP4 regulates proinflammatory cytokine expression, this article aims to demonstrate this effect in chronic epilepsy of rats. Rats were divided into four groups and were treated with different drugs: saline (Control), acetazolamide (AZA), pentylenetetrazole (PTZ), and pentylenetetrazole plus acetazolamide (PTZ+AZA). The data showed that seizures increased proinflammatory cytokine expression and that AZA significantly inhibited AQP4 expression. Overall, the results suggested that AQP4 inhibition could weaken excitotoxicity in epileptogenesis by reducing proinflammatory cytokines in the hippocampus. The findings provide a new insight into the involvement of cerebral edema insult and proinflammatory cytokines in the process of chronic epilepsy.

Key words: Chronic epilepsy; Aquaporin 4; Proinflammatory cytokines; Acetazolamide

\section{INTRODUCTION}

Epilepsy refers to a clinical syndrome characterized by recurrent and spontaneous seizures in the central nervous system (CNS). Epilepsy affects about $1 \%$ of the world population (Haut et al., 2006).

As a main water-selective channel protein in the mammalian CNS, AQP4 is located in the endfeet of astrocytes surrounding brain capillaries and forming the blood-brain barrier (BBB) (Yukutake and Yasui, 2010). Recently, considerable evidence strongly suggests that AQP4 potentially causes epilepsy when its expression is altered (Lee et al., 2004; Binder et al., 2012). AQP4 knockout mice need larger pentylenetetrazole (PTZ) doses than wildtype mice in seizure activity, while wild-type mice take a longer time than AQP4 knockout mice in generalized seizures (Binder et al., 2004). Acetazolamide (AZA), an of inhibitor of sulfonamide carbonic anhydrase (CA), can inhibit AQP4-mediated water conduction and has been studied previously (Huber et al., 2007; Tanimura et al., 2009).

Cytokines are a group of polypeptides or glycoproteins that classically mediate and regulate immune response, stimulate hematogenesis, and participate in tissue repair. Many studies on patients with epilepsy and animal models have found that cytokines and immune cells display differences; they suggested that nervous factors are predominant in epileptogenesis (Li et al., 2011a; Vezzani et al., 2011; Vezzani, 2014).

Interleukin-1 $\beta$ (IL-1 $\beta$ ), tumor necrosis factor- $\alpha$ (TNF- $\alpha$ ), and interleukin-6 (IL6) are three important cytokines in the CNS (Allan and Rothwell, 2001). Kainate-induced seizures enhance IL-1 $\beta$ immunoreactivity and are worsened by intracerebral application of

Genetics and Molecular Research 15 (3): gmr.15039012 
this cytokine. Higher levels of IL-1 $\beta$ or IL- 6 and TNF- $\alpha$ messenger RNA (mRNA) have been found in various rodent forebrain areas after kainate induction or audiogenic seizures.

Recently, it has been reported that AQP4 also participates in immunoreactivity. For example, proinflammatory cytokine secretion is significantly reduced among AQP4 knockout mice near activated astrocytes injected with lipopolysaccharide (LPS) and pro-inflammatory cytokines (Li et al., 2011b). Therefore, it is speculated that AQP4 may regulate inflammatory cytokine expression in epilepsy. This study is designed to demonstrate the effect of AQP4 inhibition on proinflammatory cytokine (IL-1 $\beta$, TNF- $\alpha$, and IL-6) expression.

It is important to identify the relationship between AQP4 changes and inflammatory cytokine formation in the hippocampus following chronic epilepsy, as this will help to clarify the pathogenesis of chronic epilepsy.

\section{MATERIAL AND METHODS}

\section{Animals}

Healthy adult Sprague-Dawley rats (220-280 g) were provided by the experimental Animal Center of Guangzhou Medical University (Guangzhou, Guangdong, China), This study was approved by Guangzhou Medical University Experimental Ethics Committee and all procedures were in accordance with International Standards. All rats were housed (five per cage) with free access to food and water, in a $12: 12 \mathrm{~h}$ light/dark cycle at a temperature of $21^{\circ}$ $23^{\circ} \mathrm{C}$ and humidity of $60 \pm 5 \%$.

\section{Drugs and experimental groups}

Chronic epilepsy model was induced in the rats by PTZ (Sigma, USA). The model group were administered a single subconvulsive dose of PTZ ( $35 \mathrm{mg} / \mathrm{kg}$, ip) every day in the morning for 28 consecutive days (Dhir, 2012). Rats were pretreated with AZA (Sigma, USA) (50 mg/kg, ip) $1 \mathrm{~h}$ prior to PTZ administration. Rats were randomly divided into four groups: saline (Control, $\mathrm{N}=20)$, AZA $(N=20)$, PTZ $(N=20)$, and PTZ+AZA $(N=20)$. All animals were evaluated for the degree of seizure every day. After the final drug administration, samples were harvested for experiments.

\section{Preparation of the rat model}

The behavior of rats injected with PTZ was recorded for $1 \mathrm{~h}$. Seizure stage was evaluated using the following standards (Racine et al., 1972): Stage 0: no response; Stage 1: hyperactivity and vibrissae twitching; Stage 2: perioral and facial muscle twitching; Stage 3: forelimb clonic seizures; Stage 4: upright, generalized tonic-clonic seizures; Stage 5: upright and falling, generalized tonic-clonic seizures with atonic seizures. The levels of seizures for every rat were recorded every day. If the rats maintained the epileptic behavior (i.e., at stage 2) for five consecutive days, it was known as kindling.

\section{Immunohistological staining}

All rats were deeply anesthetized with $10 \%$ chloral hydrate $(40 \mathrm{mg} / \mathrm{kg})$ by intraperitoneal injection. Then the rats were perfused transcardially using ice-cold phosphate- 
buffered saline (PBS) followed by $4 \%$ paraformaldehyde. The hippocampi were kept overnight in $4 \%$ paraformaldehyde at $4{ }^{\circ} \mathrm{C}$ and then in a solution of sucrose $(30 \%)$ for cryoprotection at $4^{\circ} \mathrm{C}$. The samples were then sliced into $30-\mu \mathrm{m}$-thick serial sections with cryotome CM1950 (Leica, Germany) and stored in 0.1 M ice-cold PBS. Endogenous peroxidase was blocked by incubation with $3 \%$ hydrogen peroxide containing $80 \%$ carbinol $(20 \mathrm{~min})$. Slices were first incubated in blocking solution with 10\% normal goat serum (Boster Biotechnology, $\mathrm{Wu}$ Han) for $30 \mathrm{~min}$ and the immunohistochemistry was performed for primary antibodies against AQP4 (1:200; Santa Cruz Biotechnology, USA) overnight at $4^{\circ} \mathrm{C}$. After rinsing, samples were placed at at $25^{\circ} \mathrm{C}$ in secondary anti-rabbit antibodies (1:100; Boster Biotechnology; Wu Han) for $1 \mathrm{~h}$. Finally, sections were well washed and stained with diaminobenzidine (DAB; Sigma, USA). After washing again and mounting on histological slides, counterstaining of the nuclei was performed with hematoxylin.

\section{Quantitative reverse transcription-polymerase chain reaction (Q-RT-PCR)}

Hippocampus tissue was kept in $1 \mathrm{~mL}$ TRIzol $^{\mathrm{TM}}$ reagent (Invitrogen, USA), and following the manufacturer's instructions, total RNA was obtained. The cDNA was obtained from total RNA by reverse transcription using primers. The primer pairs for amplification were as follows: $\beta$-actin, 5'-GGAGATTACTGCCCGGCTCCTA-3' and 5'-GACTCATCGTACTCCTGCTTGCTG-3'; AQP4， 5'-TGCAGCAGAGAGACATCAT-3' and 5'-CCAAAGCAGAGGGAGATGAG-3'; IL-1 $\beta$, 5'-CTGTACTCGTGGATGATG-3' and 5'-ACAGTGCATCATCGCTGTTC-3'; IL-6, 5'-CAGTTGCCTTCTTGGGACT-3' and 5'-TCTGACAGTGCATCATCGCT-3'; TNF- $\alpha, 5$ '-AGATGTGGAACTGGCAGAGG-3' and 5'-GAGCCCATTTGGGAACTTCT-3'.

The system employed was ABI Prism (Applied Biosystems, Foster City, CA, USA) using the SYBR Green PCR Master Mix Reagents (TaKaRa Biotechnology, Guangzhou, China). IL-1 $\beta$, TNF- $\alpha$, IL-6, and AQP4 mRNA transcriptions were achieved after 40 cycles of Q-RT-PCR reactions. Delta $(\Delta \mathrm{Ct})$ values of the samples were calculated by subtracting the average $\mathrm{Ct}$ value of target mRNA from the average cycle threshold $(\mathrm{Ct})$ value of the internal Control $\beta$-actin; we used the $2^{-(\Delta \Delta \mathrm{Ct})}$ parameter to show the target gene relative expression.

\section{Western blotting}

Protein concentration was estimated according to the bicinchoninic acid (BCA) protein assay kit (KeyGen Biotechnology, Nan Jing). Total protein (30 ng) was loaded onto a $12 \%$ acrylamide gel, and transferred onto polyvinylidene difluoride (PVDF) membrane after electrophoresis. Then blocking with 5\% non-fat milk was performed for $1 \mathrm{~h}$, then the rabbit anti-rat antibodies was for against AQP4 (1:2000, polyclonal Santa Cruz Biotechnology; USA), $\beta$-actin (1:2000, Abclonal; USA) overnight at $4^{\circ} \mathrm{C}$. After extensive rinsing, the membranes were developed using the anti-rabbit antibodies (1:5000, Boster, Wu Han, China) at $25^{\circ} \mathrm{C}$ for $1 \mathrm{~h}$. Bands were detected by enhanced chemiluminescence (ECL KeyGen Biotechnology, China). The relative protein expression of densitometric analysis was determined by Image J software V1.40.

\section{Enzyme-linked immunosorbent assay (IL-1 $\beta$, IL-6, and TNF- $\alpha$ quantification)}

Blood was collected during chronic epilepsy - $500 \mu \mathrm{L}$ was withdrawn from the heart

Genetics and Molecular Research 15 (3): gmr.15039012 
under $10 \%$ chloral hydrate anesthesia. The samples were immediately centrifuged ( $3000 \mathrm{rpm}$, $4^{\circ} \mathrm{C}$ ) and kept at $-80^{\circ} \mathrm{C}$. IL- $1 \beta$, IL-6, and TNF- $\alpha$ levels were analyzed by ELISA(Neobioscience Technology Co, Ltd.) according to the manufacturer's instructions.

\section{Data analysis}

All data are reported as means \pm standard error (mean $\pm \mathrm{SE}$ ), and analyzed with the SPSS version 18.0 software. Differences between groups were evaluated by the Student $t$-test or ANOVA. The results were considered significant at $\mathrm{P}$ values $\leq 0.05$.

\section{RESULTS}

\section{AZA can prolong stimulation-evoked kindling induced by PTZ}

In total, 20 rats were treated with PTZ, PTZ+AZA, normal Saline, and AZA, respectively. Following 28 days of administration, most of the rats were successfully in model condition. Injection of AZA weakened the severity of chronic seizures. The daily average seizure scores in the PTZ+AZA group were significantly lower compared with the Control group $(\mathrm{P} \leq 0.05$; Figure $1 \mathrm{~A})$ and the average time to reach kindling was significantly increased ( $\leq 0.05$; Figure $1 \mathrm{~B})$.

A

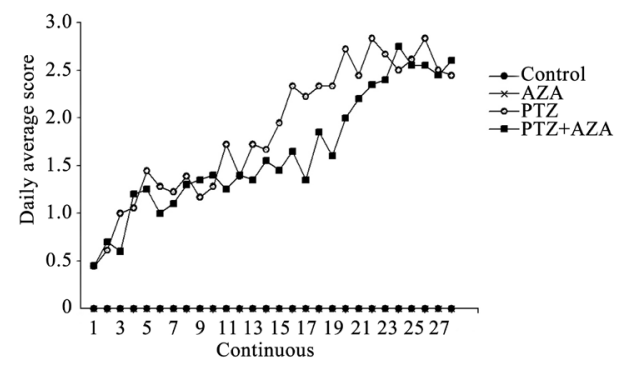

B

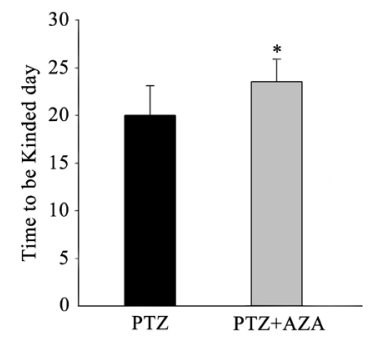

Figure 1. AZA can prolong stimulation-evoked kindling induced by PTZ. A. Daily behavior recordings showed stimulation-evoked seizure by ip injection of PTZ $(35 \mathrm{mg} / \mathrm{kg})$ and resulted in average scores for the four group. Following 28 days of treatment, the majority of the rats had reached a completely kindled condition. Daily average seizure scores in the AZA+PTZ groups were significantly lower compared with those of the model Control group $(\mathrm{P} \leq 0.05)$. However, no significant difference in the kindling rate was observed between the AZA+PTZ and PTZ groups. B. The pretreatment of AZA $(50 \mathrm{mg} / \mathrm{kg})$ decreased the average time to kindling day compared with that of the PTZ group $(* \mathrm{P}<0.05$, versus group treated with $\mathrm{PTZ})$.

Genetics and Molecular Research 15 (3): gmr.15039012 


\section{Immunostaining of AQP4 in CA3 hippocampus was primarily observed around brain microvessels}

Immunostaining of AQP4 demonstrated that AQP4 was localized in astrocytes around microvessels in each group. The staining was mainly in regions such as CA3 in the hippocampus (Figure 2).
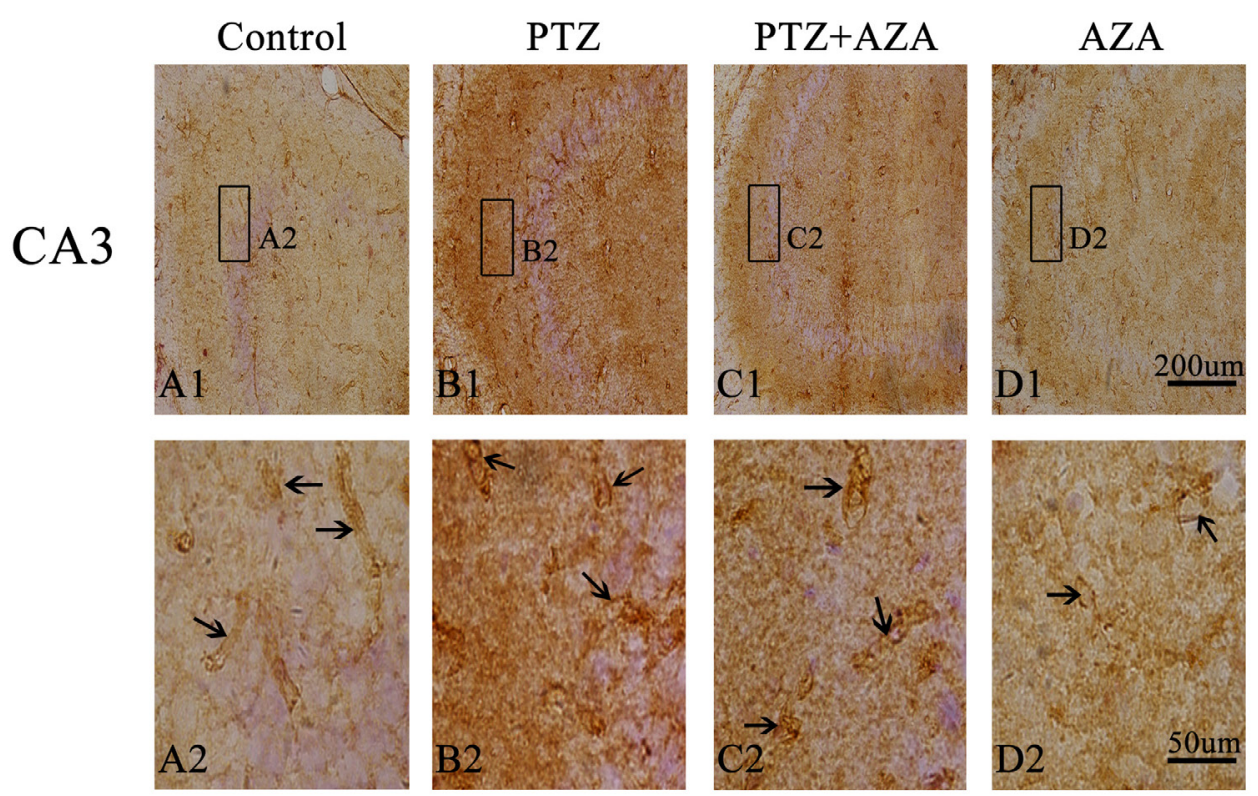

Figure 2. Immunostaining of AQP4 in CA3 hippocampus was primarily shown around brain microvessels. A. In the Control hippocampus CA3, AQP4 immunoreactivity was detected around microvessels. B. C. and D. AQP4positive staining in different groups. Scale bars 200 or $50 \mu \mathrm{m}$.

\section{AZA decreased levels of AQP4, IL-1 $\beta$, IL-6, and TNF- $\alpha$ mRNA in rat hippocampus during epileptogenesis}

We next investigated whether the inhibition of AQP4 could decrease the levels of AQP4, IL-1 $\beta$, IL-6, and TNF- $\alpha$ mRNA. As shown in the AZA group, AZA could downregulate AQP4 mRNA expression $(\mathrm{P} \leq 0.05)$. AQP4 mRNA expression level was increased in the PTZ group when compared with the Control group $(\mathrm{P} \leq 0.05)$. In addition, the level of AQP4 mRNA was decreased in the PTZ+AZA group when compared with the PTZ group $(\mathrm{P} \leq 0.05)$ (Figure $3 \mathrm{~A})$. IL-1 $\beta$, TNF- $\alpha$, and IL-6 mRNA levels showed a large increase in the hippocampus of the PTZ group when compared with the Control group $(\mathrm{P} \leq$ $0.001)$. In contrast, the PTZ+AZA group showed an important decrease in IL-1 $\beta(P \leq 0.01)$, IL-6 (P $\leq 0.001)$, and TNF- $\alpha$ mRNA $(\mathrm{P} \leq 0.05)$, when compared with the PTZ group. IL$1 \beta$, IL-6, and TNF- $\alpha$ mRNA in the AZA group presented similar values compared with the Control group (Figure 3B, C, D). 

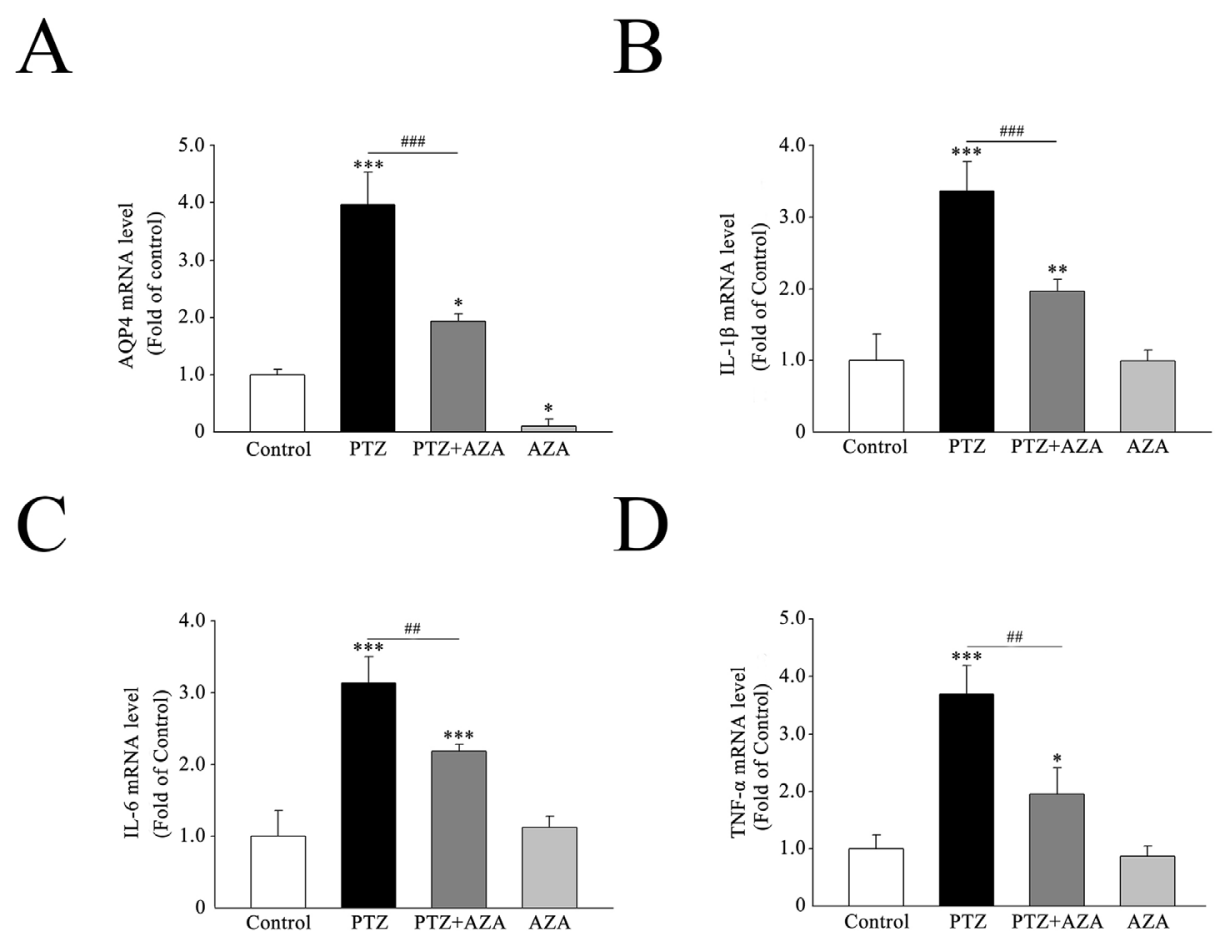

Figure 3. AZA decreased levels of IL-1 $\beta$, IL-6, and TNF- $\alpha$ mRNA in rat hippocampus during epileptogenesis. A. Treatment with PTZ increased the AQP4 mRNA but treatment with AZA decreased the AQP4 mRNA levels in hippocampus. The data show that AQP4 mRNA levels in the PTZ+AZA group was higher than that in the Control group. B. C. and D. IL-1 $\beta$, IL-6, and TNF- $\alpha$ genes were prominently upregulated during epileptogenesis in the hippocampus. Data analysis indicated that there is no significant difference between the Control and AZA groups. In the PTZ+AZA group, AZA decreased proinflammatory genes compared with the PTZ group. Bar graphs show that AZA could decrease the IL-1 $\beta$, IL-6, and TNF- $\alpha$ mRNA levels during epileptogenesis. Versus Control group with normal saline, ${ }^{*} \mathrm{P} \leq 0.05$ and $* * * \mathrm{P} \leq 0.001$; versus group treated with $\mathrm{PTZ}$, ${ }^{\#} \mathrm{P} \leq 0.01$, and ${ }^{\#} \mathrm{P} \leq 0.001$. Differences between groups were evaluated using the Student's $t$-test or one-way ANOVA.

\section{Chronic epilepsy could upregulate the expression of AQP4 protein}

Western blotting showed that AQP4 protein levels were different in the different groups. AQP4 protein levels in the PTZ groups showed a larger increase in the hippocampus during the chronic period compared with other groups $(\mathrm{P} \leq 0.001)$. The group treatment with PTZ+AZA compared to the Control group still resulted in increased AQP4 protein expression $(\mathrm{P} \leq 0.05)$. These data suggested that AZA could restrain the expression of AQP4 in the hippocampus (Figure 4).

\section{Inhibition of AQP4 impacted on the serum level of IL-1ß, IL-6, and TNF- $\alpha$ during epileptogenesis}

Finally, we observed the effect of the AZA on proinflammatory cytokines in rat serum. An overview of the levels at each condition measured is shown in Figure 4. Baseline levels 
A

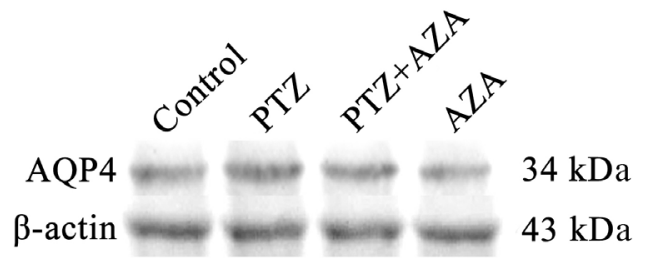

$\mathrm{B}$

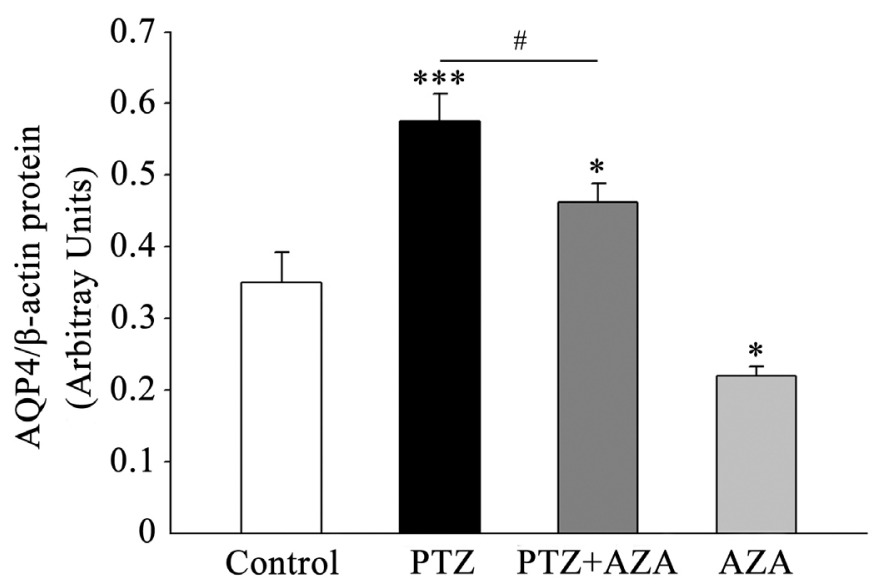

Figure 4. Chronic epilepsy could upregulate the expression of AQP4 protein. A. Protein bands show the expression of AQP4 in each group. In the PTZ group, AQP4 was significantly increased. The effects of AQP4 inhibitor AZA were also demonstrated. However, the AQP4 protein level in the PTZ+AZA group was still higher than that in the Control group. B. Bar graphs show the effect of AZA on AQP4 expression with western blotting analysis. ${ }^{*} \mathrm{P} \leq 0.05$, $* * * \mathrm{P} \leq 0.01$. "Versus group treated with $\mathrm{PTZ}, \mathrm{P} \leq 0.05$.

of IL-1 $\beta$, IL-6, and TNF- $\alpha$ plasma were taken from the Control group (as reference Control levels). In chronic epileptic phases, IL-1 $\beta$, IL-6, and TNF- $\alpha$ levels obviously increase (P $\leq$ $0.01, \mathrm{P} \leq 0.001$, and $\mathrm{P} \leq 0.001$, respectively). We also measured IL-1 $\beta$, IL- 6 , and TNF- $\alpha$ levels in plasma in the PTZ+AZA group and compared this with levels after PTZ-induced chronic epilepsy. The levels of IL-1 $\beta$ and IL-6 in the PTZ+AZA group were lower than in the PTZ group $(\mathrm{P} \leq 0.01, \mathrm{P} \leq 0.001$, respectively), but higher than Control levels $(\mathrm{P} \leq 0.05, \mathrm{P} \leq 0.01$, respectively). However, AZA did not make any significant difference in TNF- $\alpha$ between the PTZ and the PTZ+AZA groups. It is interesting to note that the plasma levels of inflammatory cytokines from AZA groups were not different compared to baseline. In the PTZ group, there was a huge increase in plasma levels of IL- $1 \beta, \mathrm{IL}-6$, and TNF- $\alpha$, indicating that it is possible to detect an inflammatory response in blood to show the chronic epilepsy condition using this method (Figure 5).

Genetics and Molecular Research 15 (3): gmr.15039012 


\section{A}

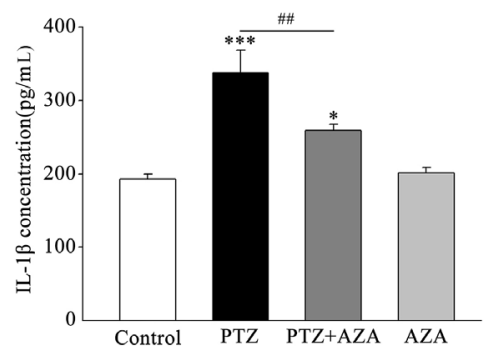

B
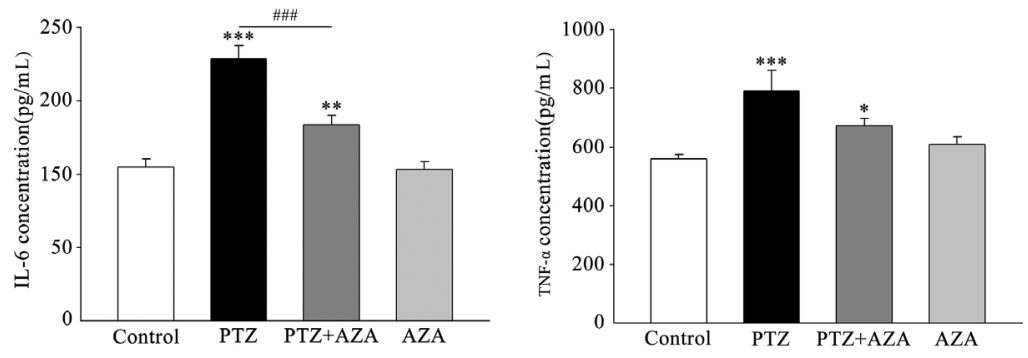

Figure 5. Inhibition of AQP4 impacted on the serum levels of IL-1 $\beta$, IL-6, and TNF- $\alpha$ during epileptogenesis. A. B. and C. IL-1 $\beta$, IL-6, and TNF- $\alpha$ showed an increased expression in the PTZ group when compared with the Control group. In addition, there was no significant difference for IL-1 $\beta$, IL-6, and TNF- $\alpha$ between the Control group and the AZA group. A. and B. The PTZ+AZA group showed an important decrease in IL-1 $\beta$ and IL- 6 when compared with PTZ group. C. However, AZA did not make a significant difference in TNF- $\alpha$ between the PTZ and PTZ+AZA groups. *Versus Control group; ${ }^{*}$ versus the $\mathrm{PTZ}$ group $\left({ }^{*} \mathrm{P} \leq 0.05,{ }^{*} \mathrm{P} \leq 0.01,{ }^{*} * * \mathrm{P} \leq 0.001 ;{ }^{*} \mathrm{P} \leq 0.01\right.$, $\left.{ }^{\#} \mathrm{P} \leq 0.001\right)$. The difference between groups was evaluated using one-way ANOVA.

\section{DISCUSSION}

Epilepsy refers to a CNS clinical syndrome characterized by the recurrence of sudden, excessive and synchronous ultra-discharge of neurons. PTZ, as a gamma aminobutyric acid (GABA) antagonist, can induce temporal lobe epilepsy in rodents. The electroencephalogram (EEG) and pathological changes are similar to those in humans in models of seizures induced by PTZ.

AQP4 was first described by the presence of the mRNA in the hypothalamic supraoptic nuclei and perivascular brain regions, and it has been frequently studied since 1994 (Jung et al., 1994). AQP4 is deleterious in edema formation because it facilitates the entry of water into astrocytes. Moreover, the pathogenesis of epilepsy involves the glial water channel aquaporin-4 (AQP4) (Binder et al., 2012).

In the CNS, glial cells secrete cytokines influencing the immune system. Caused by glial activation in chronic pathology, epileptogenesis and nerve damage result in proinflammatory transformation that maintains chronic pathological activation of astrocytes or microglia.

The relationships between AQP4 expression and inflammatory cytokines have been extensively studied in CNS diseases (Ikeshima-Kataoka et al., 2013). However, no study 
has been conducted to explore whether the inhibition of AQP4 water channels can modulate chronic proinflammation in the PTZ-induced animal model. Thus, this paper aims to focus on this aspect. This study attempts to identify whether changes in expression of IL-1 $\beta$, IL-6, and TNF- $\alpha$ can respond to AQP4 expression, with the aim of understanding more about the excitability mechanisms of neurons in epilepsy.

It was found in the study that AZA decreases AQP4 in the normal brain. Carbonic anhydrase $(\mathrm{CA})$ is the enzyme that is involved in enzyme-catalyzed reaction among $\mathrm{CO}_{2}$, $\mathrm{H}^{+}, \mathrm{HCO}_{3}$-and $\mathrm{H}_{2} \mathrm{O}$ (Igarashi et al., 2013). In addition, this also proves that consecutive administration of AZA prevents PTZ-induced chronic epileptic reaction in rats.

In this study, AQP4 immunohistochemistry showed that AQP4-labeling claybank granules are primarily located in vessels in the hippocampus cornu ammonis 3 (CA 3) region. Moreover, AQP4 is present in limited amounts in astrocyte endfeet facing the blood vessel (Aoyama et al., 2012). The results from the Control group extended to previous observations, which provided data on the distribution of AQP4 immunolabeling in normal human cerebral cortex with some glial markers, and the associated location of the microvasculature (Medici et al., 2011). It is suggested that the CA3 region of the chronic epilepsy hippocampus may not only contain an increased AQP4 level but also an increased density of microvessels and glia.

Interestingly, in our data there is no significance regarding IL-1 $\beta$, IL-6, and TNF- $\alpha$ levels in the AZA treatment alone group compared with the Control group. However, the data from the AZA+PTZ group indicated decreasing inflammatory cytokine expression in the hippocampus. It is also suggested that inhibition of AQP4 can decrease inflammatory cytokines during PTZ-induced chronic epilepsy.

Usually cytokines are detected in soluble form. A large number of clinical or animal studies have shown that cytokines can be measured in various body fluids. They provide a perspective into the pathogenetic process of inflammation.

ELISA was used to study plasma cytokines, showing the presence of chronic proinflammation cytokines in chronic seizure. The study also shows that AZA significantly decreases IL- $1 \beta$ and IL- 6 but not TNF- $\alpha$ and that the levels of IL-1 $\beta$, IL-6, and TNF- $\alpha$ are still higher than those of the Control group. The result is consistent with the level of mRNA, and it suggests that other mechanisms also help to produce proinflammation cytokines in epileptogenesis. However, another study indicates that blood plasma inflammation may not be a reliable biomarker for temporal lobe epilepsy (Holtman et al., 2013), and chronic epileptic state in temporal lobe epilepsy can also be found, even without intracerebral inflammation (Aalbers et al., 2014), indicating that an increase in plasma cytokines may be model specific or seizure-type specific (Bauer et al., 2009).

Many articles have reported that cytokine expression is regulated by the immune system. These cytokines, acting as mediators, increase the onset of brain damage in seizures (Li et al., 2011a). In addition, various cytokine storms can cause neurotoxicity and neuronal degeneration of brain tissue. In another study, peak proinflammatory cytokine effects appear after $6 \mathrm{~h}$ in status epilepticus (Ravizza and Vezzani, 2006). The upregulation is transient though no basal levels are recovered after onset.

Long-term expression of IL- $1 \beta$ performed in epileptogenesis suggested that the chronic inflammatory cytokines may be involved in the pathogenesis of idiopathic epilepsy (Vezzani et al., 2008).

In some studies, proinflammatory cytokine has also been shown to induce the AQP4 gene, and protein could be detected in cultured astrocytes (Bartfai et al., 2007). Based on 
the above studies, we hypothesize that the upregulation of inflammatory cytokines induced by seizures simulates brain insults, including neurodegeneration, BBB damage, and even brain edema, by involving the activation of nuclear transcription factor-kappa gene binding (NF-кB), cyclooxygenase-2 (COX-2), complement system and chemokines (Vezzani et al., 2011). These pathologic changes prolong stimulation of proinflammatory signals and cause persistent inflammatory reaction in the brain. This may help to build a pathologic substrate (such as neurodegeneration, neuronal hyperexcitability, and BBB damage), participating in epileptogenesis or reinforcing seizures.

The study data show that the decrease in AQP4 expression can downregulate proinflammatory cytokines, but the PTZ+AZA group still presents significant differences compared with the Control group. It is possible that another pathological transformation contributes to inflammatory cytokines.

To confirm the assumption regarding AQP4 regulation of proinflammatory activity in the pathogenesis of epilepsy and sequelae, further studies of animals or clinical patients are required. Early detection of brain injury and intervention may prevent disease progression and deteriorating neurological complications.

\section{Conflicts of interest}

The authors declare no conflict of interest.

\section{ACKNOWLEDGMENTS}

Research supported by the Guangzhou Municipal University Research Program (\#2012D001 and \#2012C128), the Guangzhou Municipal Science and Technology Program (\#2013J4100103 and \#11C32020697), 2013, of the enterprise Technology Research and Development and Upgrading Projects of Special Funds (\#2013B021800191), and the Hubei Department of Education Science and Technology Research Project (\#B2016135).

\section{REFERENCES}

Aalbers MW, Rijkers K, Majoie HJ, Dings JT, et al. (2014). The influence of neuropathology on brain inflammation in human and experimental temporal lobe epilepsy. J. Neuroimmunol. 271: 36-42 http://dx.doi.org/10.1016/j. jneuroim.2014.03.016.

Allan SM and Rothwell NJ (2001). Cytokines and acute neurodegeneration. Nat. Rev. Neurosci. 2: 734-744 http://dx.doi. org $/ 10.1038 / 35094583$.

Aoyama M, Kakita H, Kato S, Tomita M, et al. (2012). Region-specific expression of a water channel protein, aquaporin 4, on brain astrocytes. J. Neurosci. Res. 90: 2272-2280 http://dx.doi.org/10.1002/jnr.23117.

Bartfai T, Sanchez-Alavez M, Andell-Jonsson S, Schultzberg M, et al. (2007). Interleukin-1 system in CNS stress: seizures, fever, and neurotrauma. Ann. N. Y. Acad. Sci. 1113: 173-177 http://dx.doi.org/10.1196/annals.1391.022.

Bauer S, Cepok S, Todorova-Rudolph A, Nowak M, et al. (2009). Etiology and site of temporal lobe epilepsy influence postictal cytokine release. Epilepsy Res. 86: 82-88 http://dx.doi.org/10.1016/j.eplepsyres.2009.05.009.

Binder DK, Oshio K, Ma T, Verkman AS, et al. (2004). Increased seizure threshold in mice lacking aquaporin-4 water channels. Neuroreport 15: 259-262. http://dx.doi.org/10.1097/00001756-200402090-00009

Binder DK, Nagelhus EA and Ottersen OP (2012). Aquaporin-4 and epilepsy. Glia 60: 1203-1214 http://dx.doi. org/10.1002/glia.22317.

Dhir A (2012). Pentylenetetrazol (PTZ) kindling model of epilepsy. Curr. Protoc. Neurosci. Chapter 9: 37 10.1002/0471142301.ns0937s58.

Haut SR, Bigal ME and Lipton RB (2006). Chronic disorders with episodic manifestations: focus on epilepsy and migraine.

Genetics and Molecular Research 15 (3): gmr.15039012 
Lancet Neurol. 5: 148-157 http://dx.doi.org/10.1016/S1474-4422(06)70348-9.

Holtman L, van Vliet EA, Aronica E, Wouters D, et al. (2013). Blood plasma inflammation markers during epileptogenesis in post-status epilepticus rat model for temporal lobe epilepsy. Epilepsia 54: 589-595 http://dx.doi.org/10.1111/ epi.12112.

Huber VJ, Tsujita M, Yamazaki M, Sakimura K, et al. (2007). Identification of arylsulfonamides as Aquaporin 4 inhibitors. Bioorg. Med. Chem. Lett. 17: 1270-1273 http://dx.doi.org/10.1016/j.bmcl.2006.12.010.

Igarashi H, Tsujita M, Suzuki Y, Kwee IL, et al. (2013). Inhibition of aquaporin-4 significantly increases regional cerebral blood flow. Neuroreport 24: 324-328 http://dx.doi.org/10.1097/WNR.0b013e32835fc827.

Ikeshima-Kataoka H, Abe Y, Abe T and Yasui M (2013). Immunological function of aquaporin-4 in stab-wounded mouse brain in concert with a pro-inflammatory cytokine inducer, osteopontin. Mol. Cell. Neurosci. 56: 65-75 http://dx.doi. org/10.1016/j.men.2013.02.002.

Jung JS, Bhat RV, Preston GM, Guggino WB, et al. (1994). Molecular characterization of an aquaporin cDNA from brain: candidate osmoreceptor and regulator of water balance. Proc. Natl. Acad. Sci. USA 91: 13052-13056. http://dx.doi. org/10.1073/pnas.91.26.13052

Lee TS, Eid T, Mane S, Kim JH, et al. (2004). Aquaporin-4 is increased in the sclerotic hippocampus in human temporal lobe epilepsy. Acta Neuropathol. 108: 493-502 http://dx.doi.org/10.1007/s00401-004-0910-7.

Li G, Bauer S, Nowak M, Norwood B, et al. (2011a). Cytokines and epilepsy. Seizure 20: 249-256 http://dx.doi. org/10.1016/j.seizure.2010.12.005.

Li L, Zhang H, Varrin-Doyer M, Zamvil SS, et al. (2011b). Proinflammatory role of aquaporin-4 in autoimmune neuroinflammation. FASEB J. 25: 1556-1566 http://dx.doi.org/10.1096/fj.10-177279.

Medici V, Frassoni C, Tassi L, Spreafico R, et al. (2011). Aquaporin 4 expression in control and epileptic human cerebral cortex. Brain Res. 1367: 330-339 http://dx.doi.org/10.1016/j.brainres.2010.10.005.

Racine R, Okujava V and Chipashvili S (1972). Modification of seizure activity by electrical stimulation. 3. Mechanisms. Electroencephalogr. Clin. Neurophysiol. 32: 295-299 http://dx.doi.org/10.1016/0013-4694(72)90178-2.

Ravizza T and Vezzani A (2006). Status epilepticus induces time-dependent neuronal and astrocytic expression of interleukin-1 receptor type I in the rat limbic system. Neuroscience 137: 301-308 http://dx.doi.org/10.1016/j. neuroscience.2005.07.063.

Tanimura Y, Hiroaki Y and Fujiyoshi Y (2009). Acetazolamide reversibly inhibits water conduction by aquaporin-4. J. Struct. Biol. 166: 16-21 http://dx.doi.org/10.1016/j.jsb.2008.11.010.

Vezzani A (2014). Epilepsy and inflammation in the brain: overview and pathophysiology. Epilepsy Curr. 14 (Suppl): 3-7 http://dx.doi.org/10.5698/1535-7511-14.s2.3.

Vezzani A, Balosso S and Ravizza T (2008). The role of cytokines in the pathophysiology of epilepsy. Brain Behav. Immun. 22: 797-803 http://dx.doi.org/10.1016/j.bbi.2008.03.009.

Vezzani A, French J, Bartfai T and Baram TZ (2011). The role of inflammation in epilepsy. Nat. Rev. Neurol. 7: 31-40 http://dx.doi.org/10.1038/nrneurol.2010.178.

Yukutake Y and Yasui M (2010). Regulation of water permeability through aquaporin-4. Neuroscience 168: 885-891 http://dx.doi.org/10.1016/j.neuroscience.2009.10.029.

Genetics and Molecular Research 15 (3): gmr.15039012 